Huan and Chesterfield, of inconsiderable extent, and valuable only for their guano deposits, the "Loyalties," consistlep," and isle of Pins, the latter at the south, the former at
northern extremity of the main land; there are numerous nortbern extremity of the main land; there are numerous
ot ber islands,particularly at the nortberu end, but of course as they lie close to Caledonia they require no special note. likely to small extent of available land the island is not sense. Already the quantity of cattle exceeds the demand, ant respect, it being impossible to grow sugar or maize, for which crops the soil and climate seem particularly adapted in account of the locusts. Coffee grows well in certain
places, and its quality, to judge from the exbibition prizes, seems far above the average, but then it is one of those crop bacco, I fancy, will be in the future principally cultivated but at present little attention is paid to it.

But if, from the above causes, Caledonia presents little temptation to the ordinary emigrant, to the mining cap-
italist she offers a splendid field for enterprise. The island italist she offers a splendid field for enterprise. The island
has been described as one vast bed of minerals, and allowhas been described as one vast bed of minerals, and allow. which doubtless the island took its name, contain for the
most pari. the real riches of the colonv, in the shape of nickel ore, several mines of which are being worked at this

It is now seven or eight years since nickel mining first
attracted the attention of local capitalists, but the difficulty of smelting, want of market, etc., caused the whole industry to be suspended for some years. Thanks, however, to the
determined spirit and enterprise of the leading mive owner, a company was formed in France who reopened the works about four years ago, and bave, in spite of the most extraor This company own the only smelting works at present in
the colony; they send 50 tons of 70 per cent. metal ever month to France, where it undergoes the final refinement. Their mines at "Trio" produce about 600 tons per month. my own experience in otber mines fancy it would be about

7 per cent. being found close to the surface; still their number is so ant, that doubtless nickel mining will become the " special the "Bel Air" nickel mine at "Houailon" gave 7,000 or 8,000 tons of good ore before being declared worked out, The cost of extracting ore from the "Tchio" mines, smelting works, is just £200 per ton. There is also a company known as the Scotch company,
but if they are dcing anything, as yet I bave not heard of

it. Messrs. Balland et Cie. possess or work an importan mine at "Koua," although the mine has not been working
many months, I heard the manager bad guarauteed a thou
sand tons by Christmas. Copper mining, 10o, will doubtless become an important in dustry. Hitherto onlyone firm bave seriouslyinterested themlions have been confined to the working of the "Balade"
mine, situated on the banks of the largest river of the colony at the north end; but lately they bave become sole possessors
of several otber rich mines in its immediate vicinity, by the of several otber rich mines in its immediate vicinity, by the
simple but effective process of starving out the other share bolders and then purchasing their scrip at a nominal figure
In one of them, the "Diahot," an extraordinary rich lode 11 one of them, the "Diahot," an extraordinary rich lode
was almost immediately di covered on the resumption of
work. The Balade mine bad, up to date, produced about w0,000 to 50,000 tons of $15 \%$ to $18 \%$ ore.
There is also a copper mine being worked, or rather proThere is also a copper mine being worked, or rather proas yet, have not been satisfactory,; The same owners possess surface indications-if the account I beard of it was truewill turn out to be very rich; in fact, the northern part of the island seems to be as rich in copper as the south is in
nickel. There are several chrome cobalt aud antimony mines being worked. I know that considerable quantities of the
two first mentioned ores bave been shipped, but have no reliable figures to give you.
There are two gold mines declared, one of which, the
Fern Hill, bas lately resuived work. It was a tolerably good Fern Hill, bas lately resurved work. It was a tolerably good mine on first starting, but having given £28,000 worth of
gold, was closed until lately to give time to experiment
with the pyrites in which the gold is now found.

The geological formation of Caledonia is not in favor,
theoretically, of its ever becoming a great gold producing theoretically, of its ever becoming a great gold producing those causes which in otber lands have produced so abun-
dantly the Silurian and other metamorphic gold bearing strata, while the formations belonging to the Tertiary system, so rich in Australia in alluvial gold found in the beds of absent; neither bave I observed the usual evidences of the glacial epoch sbown by bowlder drift, furrowed or glacier
groned bowlders, and Pleistocene accumulation generally. Volcanic action, as far as can be gathered from surface in of the island, since when the usual recent igneous rocks met
with elsewbere, as derupting, interstratifying, or overlying
the original strata, are completely winting.

While the primary rocks, represented by serpentine, occupy fully one-third of the island, producing nickel, chrome cobalt, antimony, etc., the middle part is formed as a rule by the oldest metamorphic rocks, such as gneiss, mica schist,
with their varieties, although in places, particularly on the
west coast, slates of seemingly later origin may be seen flank west coast, slates of seemingly later origin may be seen flank-
ing the older strata.
Generally speaking, it may be said that Caledonia is Generally speaking, it may be said that Caledonia is of
very ancient formation; even the sandstones are decidedly The Carboniferous system is represented by strata (sand stonej showing coal in ibe neighborbood of " "Noumea" and places, as at “ Nont d'Or," it can be traced from the sea un-
til, at a short distance, merely superimposed on the Plutonic rock. The government is essentially autocratic, considering its that of other trout. If one succeeds in catching these de
ature and the great power placed in the bands of a few structive individuals no more fish will be eaten, for in the individuals. The fact that re are governed $80 \mathrm{well}$ a $\mathrm{we}$ shallow bronks there will rarely be any other fish of prey
are, speaks much in favor' of the French national char- Trout do not like the company of other fish; it is well, there-

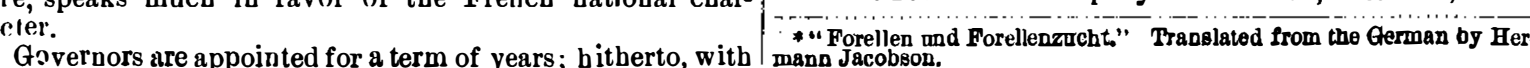

fore, to keep them separate from other fish a s much as possi-

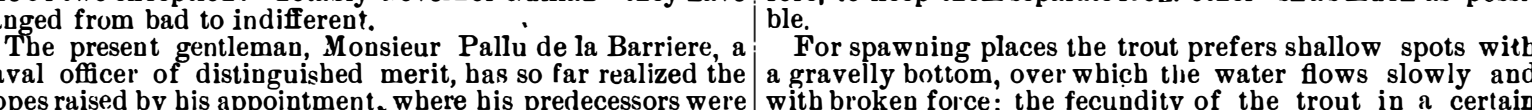
copes raised by bis appointment, where bis predecessors were
content to serve the time necessary to attain their promotions
body of water depends altogether upon the extent of suitable in their respective services, in the manner most suitable to spawning places. Whenever a brook bas large stretches of brough to bear on the Augean work be bas undertaken be assumed with a great deal of probability that it it may
a grand fund of energy and earnestness of purpose, while bis trout. For supplying trout with food it is well if there are \begin{tabular}{l|l} 
onesty and good intentions are above suspicion. & althourb the French bave been in possession of the island \\
occasionally places where the botom is muddy or peaty; a \\
slow current is also much to be preferred to a rapid current
\end{tabular}

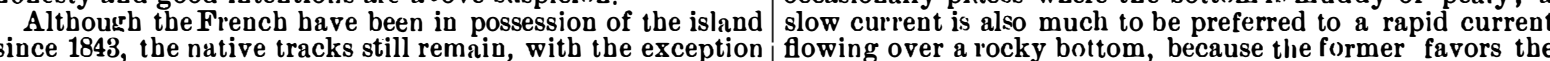
since 1843, the native tracks still remain, with the exception flowing over a rocky bottom, because the former favors the
of a few score miles of road leading from the capital, fovelopment of witer plants and small aquaticanimals. Trout the only means of communication by land; but this
state of things will in two months more be considerably
ly over their rocky beds, because they like the character of modifed, as by that time a bridle track will be couppleted
round the island, and bis Excellency bas declared his inten-
the water; but they remain small, and do not get very fat;
while slowly flowing rivers, baving muddy bottoms, but fed tion of making the tour on borseback. Doubtless a marine road will shortly also be made to ena-
ble coasters to sail between the reef and mainland on the west coast. A little dynamite and intelligence would, I
think, sonn work wonders in this respect. The blasting of think, sonn work wonders in this respect. The blasting of
few rocks in some places would open up miles of clear a few rock
channel.

\section{RARE FISHES}

A LARGE number of rare and curious specimens of deep
sea fishes have just been received by Prof. Gill, of the Sea fishes have just been received by Prof. Gill, of the
Smithsonian Institution. They were caught by the crew of
lbe Fish Commission steamer Albatross. the latter baving just returned from an exploring expedition in mid.ocean The Albatross was absent two months, during which time
fisb were captured representing thirty new species, twenty
new genera. aud three families. The Britisb explorin steamer Cballenger du ring a three years' cruise only secured specimens representing fourteen new generi. The wonder-
ful success of the Albatross is therefore emphasized by ful success of the Albatross is therefore emphasized by
scientific men in this city. The fish are caught by means of
a dredge or net, which is subk very often to a depth of a dredge or
3,000 fathoms

Among the strange denizens of the deep caught during
the cruise are following: 'The Anchenichthy, or fish with ne cruise are following: The Anchenichthy, or fish with a
neck. This specimen resembles an eel, bas a well formed
neck, and was caught at a great depth. The Gastrostonius Bairdii (named after Prof. Baird). This odd looking fish Was described in the Popular Science Monthly as "the won-
der of the deep sea." It is a variety of the devil fish. The jaw bones are seven times as long as the cranium, and are together, forming a broad poucb. The fish swims about with its pouch open, acting in the capacity of a seine. mouth by means of suction. The " Baird fish" resembles a scaly, tail. The Cryptopsaras, or " ang!er with concealed rod," is a most remarkable specimen. It bas a very large baited line, which floats above the body. Small fish nibble
at the line, and are captured by the "angler." The bait is
a ball of jelly-like matter, which is so sensitive that-instant a ball of jelly-ike matter, which is so sensitive that instant the "angler" " fumily is perfectly lilind. It is known as the
Typlopisaras, or "blind angler." This remarkable tish fisher was never beard of until the recent cruise of the Albatross,
and it is said to inhabit the sea 2,000 fathoms below the surface. The Hypercharistus Tanneri, or fish with upper pectoral
rays or finger separate, is a queer shaped and vicious little ner, of the Albatross, whose band the little creature tried to bite when landed on the deck of the steamer with the deep
sea selne. It is jet black, and bas teeth like a circular saw. The Neurichthyids, or snipe eel, is a genuine curiosity. Its
body resembles that of an ordinary eel, while the bead is a facsimile of that of the common marsh snipe which abound in Maryland and Virginia. The tape fish is another inter-
esting fish. It is of the size and thickness of ordinary tape, and when in the water is pe

There are several other remarkable specimens. They
The appear in the illustrated annual reports as fish discovered the United States Fish Commission. They vill also prob bly be placed upon exhibition in the
Smitbsonian.-National Republican.

\section{'TROUT AND TROUT CULTURE.*} By R. A. Koss.

THE brook trout belongs to a family of fish the members of which are distinguished for their delicate flavor, and
cumong which the salmon, the king among all food-fish, oc most valuable fresb water fish, and recommends itself to the pisciculturist by many excellent qualities. The clearer colder, and more rapid in their flow the waters are in which It seetns as if nature took special care not to make its appear
ance too striking, so as to attract the attention of its enemies.
of whom man, after all, is not the worst. The trout, which of whom man, after all, is not the worst. The trout, which
in brooks reaches a weight of about three pounds, seldom more, is a very bardy fish, and not very choice in its food. on account of its voracity, it can be accustomed to take its
food from a man's band. It is particularly well adapted to pisciculture, because its eggs are very bardy and can easily be transported a considerable distance. Its power of diges-
tion is very extraordinary, and when well fed it grows quicktion is very extraordinary, and when well fed it grows quick-
er than most other fish. Its food is exclusively animal, con-
sisting principally of insects, larve, snails, and other small animals. All these water aniuals need uquatic plants for their existence, and these plants are, therefore, necessary indirect-
ly to the trout. It cocasionally eats fisb but never shows as much liking for them as for the other articles of food mentioned above. When a number of trout living together bave
sufficient food, there will be among them but very few which eat fish, perbaps only one in a hundred, provided that the
difference of size is not ton great. The trout which eat fish difference of size is not ton great. The trout which eat fish
grow quicker than their comrades; in retired places they grow quicker than their comrades; in retired places they
lead the life of bermits, and their flesh is less delicate than by many gravelly brooks, where the fish can retire for spawnwhich fetch the highest price in the market. It is a very
general, but neverthele ss erroneous, notion that trout only general, but neverthele ss erroneous, notion that trout only
live in water which is clear and transparent as crystal; on live in water which is clear and transparent as crystal; on
the contrary, they seem not in the least disturbed by the waer being muddy, and, as we have seen, a muddy bottom
even favors their growtl. In Norway, which is famous for its delicate trout, they flourish most in rivers and brooks witl muddy bottoms, provided suitable spawning brooks are within easy reach. If there are in a body of water many stagnant places where aquatic plants grow in profusion, and
bollow banks with entangled roots of trees and similar biding places, the trout will flourish, even if the water does not
flow very freely. Thus the river Leith, in Scotland, for example, is so shallow in many places during the summer that ample, is so shallow in many places during the summer tha feet; but it possesses a series of stagnant puddles extending
for miles, which barbor an abundance of very large and delicately flavored trou

It is likewise an erroneous idea that trout require very cold to stand warm water, such as is found in the plains during
the bot season. It has been observed in Germany that trout streams reached a $t \in m$ perature of 21 , and even 26 , degrees Reaumur, without in the least injuring the tish. A warm creases their food very considerably, which is an important
item, considering their voracity. It is well, however, for item, considering their voracity.
trout streams flowing through a plain to have bere and there
along their banks bushes and sbade trees, for during the beat of the day trout love to stay in such shady places, as under
the overbanging branches and among the roots they find an the overbanging branches and among the roots they find an wind. Trout culture is made comparatively easy by the circum-
stance that no other fish stays as steadily in one place
witbout ever going far from it as the trout. Any person who lives near a stream, and is in the least observant, will be able to indicate the exact place of sojourn of this or that
particularly striking individual truut. Apart from the particularly striking individual truut. Apart from the water exteuding frequently not more than 50 to 100 feet,
which enables the proprietors of small bodies of water to use
them advan tageously for trout culture. When trout are well taken care of, they prefer to stay within narrowly confined
limits; they learn to know man, approach him without fear, and even jump out of the water to get some food which is
beld out to them, in which case, bowever, one has to be careful not to get hurt by their sbarp teelb.
If trout are wellfed theybegin to spawn when two years If trout are well fed they begin to spawn when two years
old, and it bas even bappened that trout only one year old year old ones about a thousand, and those from four to five years old even as many as two thousand. To stock a mod-
erately sized stream with trout requires at least ten thousand young fish per annum. If this bas been continued for three years one may, with tolerable certainty, count on good trout
fishing. As a general rule trout flourish better in brooks, where they take care of themselves, than in ponds, wher tion only until they are able to seek their own food. Where there is no running water they call be kept in that which is
still, provided that the latter is constantly kept pure by inlowing springs.

ing and batching establishment may take their place; and it is well known that during the last decades a great and
has been dove in the way of artificial trout culture It re quires a good deal of technical knowledge to start and superintend such establishments, but the expenses are very tri-
fling compared with the great profit. Natural trout.culture left to themselves, one thousand eggs will produce, on an
average, only one fish, while in a well conducted pisciculfrom the same number of eggs. The very waters in which trout flourish most bave frequently no suitable spawning
places, and if the supply is limited to the result of natural propagation the trout must soon die out, or, gt any rate, become very scarce. Young fry from a pisciculiural establishment
are best placed at first in small streams or brooks with a gravelly bottom and
of a wire grating.

As trout find much more food in the brooks and streams gravelly mountain streams, and consequently grow faster profitable field is bere opened to the pisciculturist. The
prejudice that trout are difficult to raise and that they are very choice in the selection of water cannot be sufficiently combated. As soon as they are able to forage for themselves
they will be satisfied with almost any kind of water, provid ed it contains sufficient food. A brook contuining pike and
perch, but no spawning places for trout, will have to be tocked with ten times as many young fry, if any good fishing is looked for, as are required for an open mountain
sream which is free from those two fisb; but by means of artificial pisciculture the necessary quantity of young fry can easily be procured.
Mr. Peard, an Englishman, bas made very practical sug. gestions for improving small trout-brooks. As we bave
seen. trout flourisb best in streams which bave not only a
gentle current of water flowing over even places, but also a gentle current of water flowing over even places, but also a are the favorite biding places and winter quarters of the fisb, plying ample nourishment for insect life, and quatities of mountain water; they are, on the contrary, very well able
to stand warm water, such as is found in the plains during bave been known to discharge mature spawn. Two year
old trout lay from two bundred to five hundred eggs, three is much less profitable, because it bas been calculated that average, only one fish, while in a well conducted piscicul-
ural establisbment eight to nine bundred fisb may be raised above-referred to (sluggish, well-shaded waters) than in 
rents. Whenever there are no such pools they can easily be bonic acid; it is very mobile and exhibits a very beautiful
made artificially, for which purpose cross dikes are construct- meniscus. Carbon disulphide freezes at about $-116^{\circ}$, and ed in the bed of the stream, at a distance of one hundred to again becomes liquid at about $-110^{\circ}$. Absolute alcobol at one bundred and fiftv feet, and strengthened by sod, sand, about $-129^{\circ}$ is thick and viscous like oil, and at about $-130^{\circ} 5^{\circ}$
and stones. Below these dikes boles are dug, three to five solidifies to a flrm mass. The more accurate numbers will and stones. Below these dikes boles are dug, three to five
feet, deep and six to seven feet long, in each of which are
be given in another paper. In the same way as referred to placed some large and several small stones; or flagstones.
The fsh are gove, the autlior endeavored to liquefy nitrogen and carfish thieves are foiled in their endeavors to catch trout wilb nets. As these dikes produce small waterfalls, the poo's are increased by every bigb water, if proper care is only taken extend several feet on the bank, so as to prevent the, water
from flowing past them; and then the soil carried along by tib from flowing past them; and then the soil carried along by the
stream will continually make the dikes stronger and stronger. stream will continually make the dikes stronger and stronger.
In our age, when it is of ten so exceedingly diffcult for a man to make a living, it is absolutely necessary for the farm er and landed proprietor to husband bis resources, and to
derive the greatest possible benefit from bis property. A stream or a pond, unless used for purposes of irrigation, tempts were even made to lay it dry, with the view of using the land thus gained to greater advantage. In our days no
landed proprietor should be found guilty of such folly. By utilizing such waters for pisciculture, the first expenses of
which are, as a general rule, very slight, a tenfold greater which are, as a general rule, very slight, a tenfold greater
profit can be realized than by laying them dry and using them for agricultural purposes. In nearly every part of our country there are thousands of such ponds and streams
which at present are entirely useless, but which if stocked with fine food fish would become a rich source of income to their owners. Of all the various brancbes of pisciculture,
trout culture is certainly the easiest and most profitable, and trout culture is certainly the easiest and most profitable, and tin U. S. Fish Commission.

EXPERIMENTS ON THE COLORS OF GEMS.

LT.-CoL. W. A. Ross, 1871, tried to obtain a blue color b dissolving, pure alumina in a pearl of borax. After enough to scratch glass. $T$ is experiment led bim to think
that the blue color of sapphire is due to its 98 per cent. of alumina, and not to the traces of any metallic oxide. In the following year experiments with lime which bad been freshly calcined and with bydrate lime, showed a remarkable and of the pearl. In 1873 be found that by dissolving pure alumina, ucder tbe blow-pipe, in a pearl of boric acid which bad been opalized by means of platinum, and adding a small
proportion of bydrate of potassium, be obtained a bluish pearl, much more rapidly and easily than by bis first ex peri-
ment. Some years later be bought, in London, a little ment. Some years later be bought, in London, a little
American wavellite. On treating the powder of this mineral under the blow-pipe, in an opalized or bydiated pearl of see that bis pearl became purple, then blue, and finally of a brilliant green. Subsequent experiments satistied bim that
altioutgh phosphoric acid had not been discovered in sapaltirough phosphoric acid had not been discovered in sap-
phire or in lapis lazuli, it may bave contributed to their coloring; for lazulite, which is similarly blue, is essentialy a phosphate of aluminum, and pure phosphoric acid is well
known to be one of the most deliquescent substances in nature. The outans which can 'be prodred by the gid of aluminum, hydrated boric acid, and hydrate of potassium, are purple, or amethyst, green, blue. Heintz bas proved
that the color of amethyst is uot due to manganese or to titanic acid. Some chemists erronenusisy attribute the green color of the emerald to a trace of cbromic acid; but chrome
dissolved in the blow-pipe pearls invariably gives a pinkisb dissolved in the blow-pipe pearls
hue.-Ann. de Chem. et de Phys.

ON THE CONDENSATION OF GASES.

A PAPER detailing results bas appeared in the Anzeiger dor Wiener Akedemie der Wissenschaften and the Compt \& Rendus, xcri., 1140. It treats of the facts arrived at by S. Von Wro-
blewski and $\mathrm{K}$. Olszewski.
They say that the results which Cailletet and R. Pictet ob They say that the results which Cailletet and $R$. Pictet ob-
tained in their valuable work "On the Liquefaction of the Gases," lead us to bope that the time is not far distant when we shall be able to as easily examine liquid oxygen in a glass tube as it is at present to look at a tube filled with carbonic
acid in the liquid state. The one condition which must of necessity be arrived at is a sufficiently low temperature. In tion to fluid ethylene as a means of reaching an exceedingly
low temperature. This gas, in a fluid state, boils under the low temperature. This gas, in a fluid state, boils under the
atmospheric pressure at $-105^{\circ}$, as measured by a thermomeatmospheric pressure at $-105^{\circ}$, as measured by a thermome-
ter of carbon disulphide. Cuilletet bimself compressed oxy. gen in a very narrow tube, and cooled it down to $-105^{\circ}$ in this fuid. Fo the moment of expansion be saw a tumultuous
ebullition; it boiled during an appreciable time, and resembled the projeetion of a liquid in the cooled part of the tube.
This ebullition was formed at a certain distance from the This ebullition was formed at a certain distance from the
bottom of the tabe. "I was not able to recognize," be goes on, "whether the liquid pre-existed or whether it formed at
the moment, because I was not able to see the separation of the moment, because I was not able to see the separation of
the liquid and the gas." constructed a new apparatus for bigher pressures, in which considerably large quantities of gas can be subjected to a pressure of to study the temperatures at the moment of expan-
sion. The experiments soon led them to the discovery of a emperature at which carbon disulphide and alcobol became solid, and oxygen is rendered completely liquid with the
greatest ease. This temperature is reached by letting liquid greatest ease. This temperature is reached by letting liquid
ethylene boil in a vacuum. The boiling point depends, of course, in sucb a case, on the goodness of the vacuum of the
pump. By the vacuum which, up to the present, it bas been pump. By the vacuum which, up to the present, it bas been $-136^{\circ}$. This low point-in fact, all the temperatures which we place on record-are measured with the bydrogev ther-
mometer. The critical temperature of that at which the liquefied ethylene boils under the pressure of one atmosphere. The latter is not $-105^{\circ}$, as at tirst it
was assumed to be, but lies between $-102^{\circ}$ and $-103^{\circ}$, as is shown by our thermometric observation. From a number of determinations which we have made we quote the
ing, which will serve to show where the point lies:

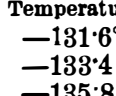

underwhinct the oxpercen
begins to liquefy.

$=131^{\circ} \cdot 6^{\circ}$ $26 \cdot 5$
$24 \cdot 8$
$22 \cdot 5$

Iiquid oxygen is colorless and as transparent as fluid cer bonic oxide. The liquefaction of these two gases is brought
about with more considerible diffculty than in the case of
oxygen, and under such similar conditions that at the mooxygen, and under such similar conditions that at the mo-
ment it is diffleult to say which of the two gases is the easier. At a temperature of about $-136^{\circ}$, and under the pressure of appears to liquefy. The glass tube with the gases appears
to be quite transparent, and no traces of liquid can be obto be quite transparent, and no traces of liquid can be ob-
served. If the gas is suddenly freed from the pressure, there is remarked in the tube containing the vitrogen a powerful
boiling un of the liquid, which is best compared with the boiling uf of the liquefied carbonic acid in a Natterer's tube when
it is placed in bot water. In the case of carbonic oxide the it is placed in hot water. In the case of carbonic oxide the
boiling does not take place in so strong a degree. If, how-
ever. the expansion be not allowed to take place so suddenly, ever. the expansion be not allowed to take place so suddenly,
and it be allowed to sink to 50 atmospheres, botb the liquefed gases, nitrogen and carbonic oxide, evaporate com-
pletely, the liquids sbow a perfect meniscus, and rapidly evaporate. The two gases can only be retained for a few
seconds in the form of liquid in the static condition. To reain them longer in that state a somewhat lower temperature must be reached than we bave at present succeeded in attain-
ing. Nitrogen and carbonic oxide in the condition of liquids ng. Nitrogen and carbonic oxide in the cond
are, botb of them, colorless and transparent.

\section{LEAD.}

LEAD is a bluish white metal of considerable brilliancy, formation of a thin film of oxide. It is so soft that it may be readily cut with a knife. or may be made to take impres-
sions, and it leavesa streak upon paper. It may be cut or sions, and it let vesa streak upon paper. It may be cut or
heaten into thin sheets, but in ductility and tenacity it is Iow
in the scale of metals. It is readily fusible at a temperature in the scale of metals. It is readily fusible at a temperature of about $625^{\circ}$, and at a highes temperature it absorbs ox ygen
rapidly from the air, and the oxide thus formed volatilizes in the form of white fumes.

The combined action of air and water on lead is a subject of great practical importance, in consequence of the metal and water pipes. The lead becomes oxidized at the surface,
and and and the water dissolves the oxide; this solution absorbs the
carbonic acid of the atmospbere, a film of bydrated oxicarbonate of lead is deposited in silky scales and a fresh por-
tion of oxide of lead is formed and dissolved, and in this way a rapid corrosion of the metal ensues. This action is materially increased by the presence of some salts, and diminished
by the presence of other salts in the water. It is much increased by the occurrence of chlorides (which, as chloride
of sodiun, is of ten present in spring water, and of nitrates of sodiun, is often present in spring water), and of nitrates ters, from the decomposition of organic matter); while it is
diminished by the sulphates phospliates and carbonates diminished by the sulpbates, phosphates, and carbonates,
and especially by carbonate of lime, which is an extremely common impurity in spring water. In the latter case, a film insoluble carbonate of lead is rapidly formed on the sur-

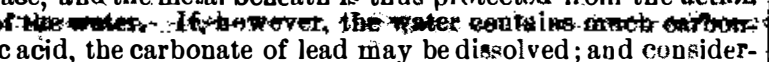
ng the dangers that arise from the use of water impregnated
with leud, cisterns constructed of slate are far preferable to Pure ones.

Pure lead is of very rare occurrence. Almost all the lead
of commerce is obtained from galena, the native sulphide of of commerce is obtained from galena, the native sulphide of
lead, by a process to be explained afterward. The lead thus obtained is of ten nearly pure, and to obtain it perfectly pure
it should be reduced with black tlux from tbe oxide left by
igniting the pure nitrate or carbonate.

The compounds of lead with oxygen are four in numberviz., a sub-oxide which is a black powder of nc import-
nce; a protoxide, which is the base of the ordinary salts of the metal; a binoxide; and red lead, which is a compound
of the two last named oxides. The protoxide is commonly of the two last named oxides. The protoxide is commonly
known as litharge. It is obtained on a large scale by the oxidation of lead in a current of air, when it forms a scaly mass
of a yellow or reddish tint. If the oxidation be effected at a emperature below that required for the fusion of oxide, a emperature below that required for the fusion of oxide, a
much used by the assayer assicot, is obtained. Litbarge is
inc it enters largely into the composition of the glaze of common eartbenivare and into
the nanufacture of glass; and it is employed in pharmacy in the manufacture of glass; and it is employed in pharmacy in forms the compound known as dbil mastic, which, from the
for ardness witb which it sets, is frequently employed to repair The most important of the salts of the protoxide of lead
efects in stong re: 1. The carbonate, which occurs native as a beautiful mineral in transparent needles or fibrous masses, and which a pigment by a process which we sball subsequently describe The carbonate is insoluble in water, unless it is largely
charged with carbonic acid. It is generally blackened by exposure to bydrosulphuric acid (sulphureted bydrogen). phate, which occurs native in white prismatic crystals, and
is formed as a beavy white precipitate on adding sulphuric acid or a soluble sulphate to a soluble lead salt. 3. The
nitrate, whicb is formed by dissolving lead or its protoxide nitrate, whicb is formed by dissolving lead or its protoxide
in dilute nitric acid. 4. The cbromates, of which the princi

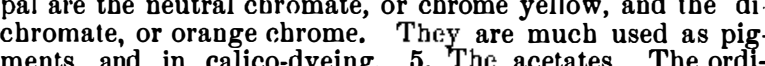
ments, and in calico-dyeing. 5. The acetates. The ordinolution of litbarge in distilled vinegar, and evaporation,
when the salt is obtained in four sided prisms, or more com. when the salt is obtained in four sided prisms, or more com
monly in a mass of confused minule white crystals, which at $212^{\circ}$ lose their water of crystallization. From its appearof sugar of lead. It is used both in medicine and the arts.
Basic acetate of lead, regarded by some chemists as a diacetate, and by others as a triacetate, and commony known as Goulard's extract, is prepared by boiling a solution of sugar
of lead with litharge, and adding alcohol, when the salts separate in minute transparent needles.

The best test for solutions of the salts of lead are the formation of a black sulphide.with hydrosulphuric acid or bydroof a white insoluble sulphate with sulphuric acid, or a solu-
ble sulphate; of a yellow chromate witb chromate
of potash; and a yellow iodide with iodide of either in the form of gas or in solution, and this is a serious
drawback to the use of lead salts as pigments. 2. The sul- potassium. All the salts of lead, insoluble in water, are solure soluble in a solution of potash. Before the blow-pipe on

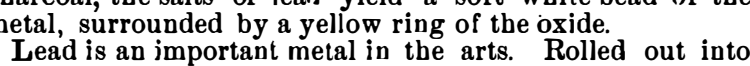
beets, it is lsrgely used for roofing bouses, for water cisterns, and for water pipes. It is also of great service in the con-
struction of large cbambers for tbe manufacture of sulpburic struction of large cbambers for tbe manulacture of sulpburic
acid. Its value in the manufacture of shot is well known. Alloyed with antimony, etc., it is largely consimed for type metal, and with tin for solder. Much lead is also required for the manufacture of pewter, Britanuia metal, etc.

for manufacture of pewter, Britannia metal, etc.
The most important compound of lead in the materia mein acetate of lead, which is administered internally ent, especially in cumbination with opium, in cases of mild domest ic cholera, and even of Asiatic cholera, and in various
forms of diarrbea. It will frequently check the purulent forms of diarrbœa. It will frequently check the purulent
expectoration in phthisis, and the profuse secretion in bronchitis. In the various forms of bernorrbage-as from the
lungs, stomach, bowels, or womb-it is employed partly witb the view of dimisbing the diameter of the bleeding vessels and partly with the object of lowering the beart's action, and
by these means to stop bleeding. The ordinary dose is two by these means to stop bleeding. The ordinary dose is $t w o$
or three grains, with balf a grain of opium, in the form of a or three grains, with balf a grain of opium, in the form of a
pill, repeated twice or thrice daily. If given for too long a porter.

A CATALOGUE containing brief notices of many important
scientific papers beretofore publisbed in the SUPPLEMENT, scientific papers beretofore publist
may be bad gratis at tbis office.

\section{Scientific American Supplement. PUBLISHED WEEKLY.}

Terms of Subscription, \$a a Year.

Sent by mail, postage prepaid, to subscribers in any part of
the United States or Canada: Six dollars a year, sent, prepaid, to any foreign country.

All the back numbers of THE SUPPLEMENT, from the
commencement, January 1,1876 , can be bad. Price, 10 cents each.

All the back volumes of The SUPplement can likewise be supplied. Two volumes are 1ssued yearly. Price of
each volume, $\$ 2.50$, stitched in paper, or $\$ 3.50$. bound in stiff covers.

Combined Rates - One copy of Scientific American and one copy of SCIENTIFIC AMERICAN SUPPLEMENT, one
year, postpaid, $\$ 7.00$.

muñ \& Co., Publishers, 261 Bxodpay. Narkerk, N. Y.

TABLF: OF CONTEN'IS.

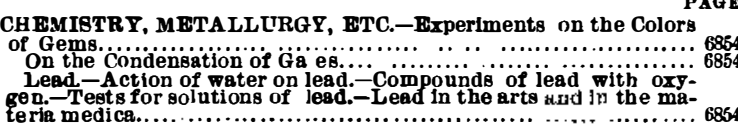

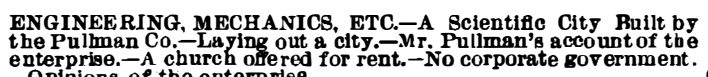

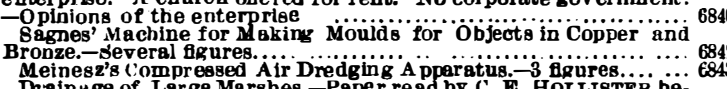

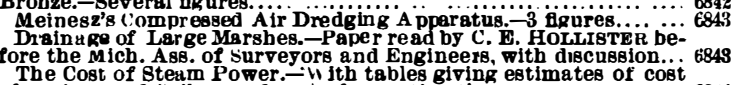

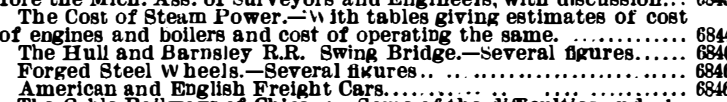

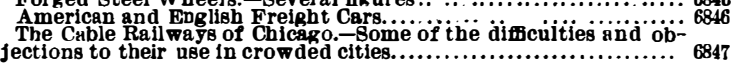

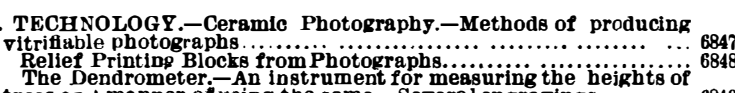

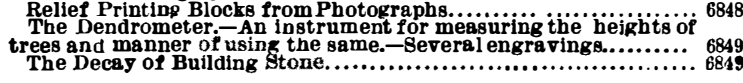

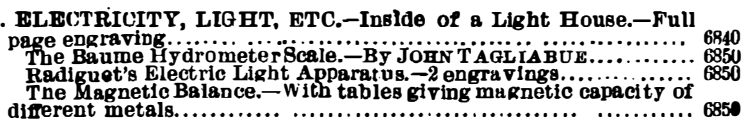
A RCETECTU RE.-Residence for the Hon. A. C. B. Bannatyne.

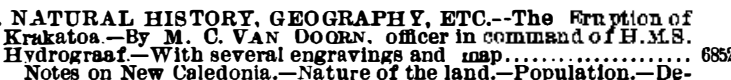

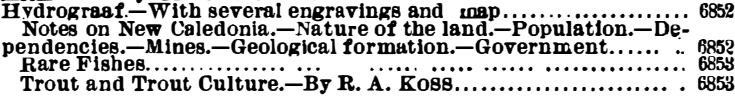

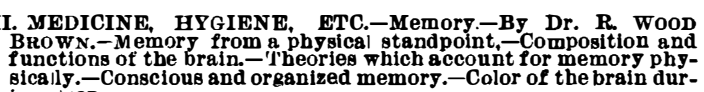

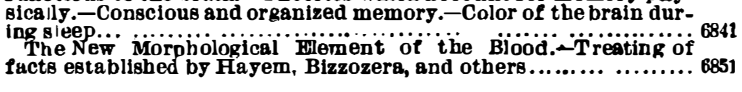

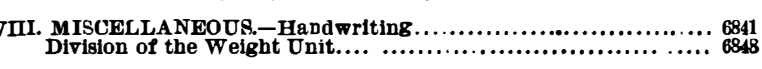

PATENTS.

\section{In connection with the Scientific American, Messrs Mons \& Co} are Solicitors of American and Foreign Patents, have haa 39 years' experiA special notice is made in the Scientific American of all Inventions patented through this Agency, with the name and residence of the
Patentee. By the immense circulation thus given, public attention is diPatentee. By the immense circulation thus given, public attention is di-
rected to the merits of the new patent, and sales or introduction often Any person wno has made a new discovery or invention can ascertain free of charge, whether a pant co.
Mone can probably be obtained; by willing to We also send free our Hand Book about the Patent Laws.
Caveats. Trade Marks, their costs. an $\gamma$ how procured. Address

MUNN \& CO.. 261 Broadway, Now York. 